\title{
THE WELFARE COST OF EXTERNAL HABITS: A QUANTITATIVE ASSESSMENT*
}

\author{
EL COSTE EN TÉRMINOS DE BIENESTAR DE LOS HÁBITOS \\ EXTERNOS: UN ANÁLISIS CUANTITATIVO
}

Manuel A. GómeZ**

\begin{abstract}
This paper quantifies the welfare cost of consumption externalities in an endogenous growth model with habit formation. Agent's utility depends on both current consumption and a reference consumption level determined by economy-wide average past consumption. Although utility may be lower in the presence of consumption externalities, the welfare loss relative to the efficient growth path is found to be very small. This result is extremely robust to variations in the parameter values. However, there are relatively important differences in the timing of the welfare loss and in generational welfare.
\end{abstract}

Key words: Welfare; Habit formation; Endogenous growth.

\section{Resumen}

Este trabajo cuantifica la pérdida de bienestar en presencia de externalidades asociadas al consumo en un modelo de crecimiento con formación de hábitos. La utilidad depende del consumo actual y de un nivel de consumo de referencia determinado por el nivel medio de consumo pasado en la economía. Aunque la utilidad puede ser menor en presencia de externalidades asociadas al consumo, la pérdida de bienestar con respecto a la solución eficiente es muy reducida. Este resultado es robusto a variaciones paramétricas. Sin embargo, hay diferencias relativamente importantes en el timing de la pérdida de bienestar y en el bienestar generacional.

Palabras clave: Bienestar, Formación de hábitos, Crecimiento endógeno.

JEL Classification: E21, D62, O41.

* The author wishes to thank the editor, Rómulo Chumacero, and an anonymous referee for their helpful comments. Financial support from the Spanish Ministry of Science and Innovation and FEDER through Grant ECO2008-04180 is gratefully acknowledged.

** Facultad de Ciencias Económicas y Empresariales, Universidad de A Coruña. Campus de Elviña, 15071 A Coruña, Spain. Phone: +34-981-167000, Fax: +34-981-167070. E-mail:mago@udc.es 


\section{INTRODUCTION}

Dynamic equilibrium models with habit formation have recently attracted a great attention in the literature because of their ability to account for some empirical facts that are difficult to explain under standard time-separable preferences. ${ }^{1}$ In models with habit formation, individuals' utility depends not only on their level of current consumption but also on how their current consumption compares to a reference level -the habits stock-. Two extreme specifications have been considered according to how the habits stock is formed. In the model with internal habits $(\mathrm{IH})$, the reference stock is formed from own past consumption levels (e.g., Constantinides, 1990, Fuhrer, 2000, and Boldrin et al., 2001). In the model with external habits $(\mathrm{EH})$, habits arise from economy-wide average past consumption (e.g., Campbell and Cochrane, 1999, Lettau and Uhlig, 2000, and Turnovsky and Monteiro, 2007). The introduction of habits formed from some external benchmark taken as given by individuals may render the competitive equilibrium inefficient. An interesting issue this raises is to quantitatively assess what is the welfare cost of consumption spillovers associated to the presence of external habits.

This paper assesses the welfare cost of consumption externalities in an endogenous growth model with habit formation. To this end, we compute the welfare loss that happens in the external-habits economy relative to the efficient externality-free internal-habits economy after a shock that reduces the capital stock. The focus of the paper is on the welfare implications of the introduction of habits into utility. Hence, we keep the production side of the economy as simple as possible, and consider that output is produced with an AK technology. ${ }^{2}$ This simplification allows isolating the effect of habits on the economy dynamics because, as it is well-known (e.g., Rebelo, 1991), the AK model with standard time-separable utility does not exhibit transitional dynamics. Therefore, the dynamics of the economy would be driven exclusively by preferences; i.e., by the presence of habits. In contrast with the simplicity of the production side of the economy, we propose a general specification of preferences which encompasses, as particular cases, the most commonly used specifications in the literature: the subtractive model (e.g., Constantinides, 1990, Campbell and Cochrane, 1999), in which individuals derive utility from the difference between current consumption and the habits stock, and the multiplicative specification (e.g., Abel, 1990, and Carroll et al., 1997, 2000), in which individuals derive utility from the ratio between current consumption and the habits stock.

1 For example, Abel (1990), Constantinides (1990) and Campbell and Cochrane (1999) try to explain the equity premium puzzle; Carroll et al. (2000) study the observed relationship between savings and growth, Lettau and Uhlig (2000) and Boldrin et al. (2001) try to fit some stylized facts of business cycles; Fuhrer (2000) studies monetary policy, Diaz et al. (2003) analyze the determination of precautionary savings and the shape of the wealth distribution, and Buraschi and Jiltsov (2007) try to explain the term structure of interest rates.

2 Previous works that have taken this approach include, e.g., Carroll et al. (1997, 2000), Shieh et al. (2000), Ferraguto and Pagano (2003), Mansoorian and Michelis (2005), Gómez (2006, 2008) and Tsoukis (2007). 
We find that the welfare loss caused by the presence of consumption externalities is very small. This result is extremely robust to variations in the parameters governing the habit-formation process: the speed of adjustment, the strength of habits in utility, the externality parameter that reflects the weight of past average consumption in the habit formation process, and the elasticity of intratemporal substitution between consumption and the habits stock. We also find that there is no welfare loss in the subtractive model, so that the competitive equilibrium of the external -or mixed- habits economy is efficient, for all the parameter configurations considered.

Two additional related issues are addressed. First, we analyze the welfare timing. In the multiplicative model, in which the elasticity of substitution between consumption and habits is unitary, welfare in the external-habits economy is always lower than that in the internal-habits economy, and the difference may be significant. The highest welfare loss is generated on impact and, thereafter, it decreases steadily toward its stationary value. However, different values of the elasticity of intratemporal substitution between consumption and habits may lead to a completely different behavior, in which the highest welfare gain is generated on impact and, thereafter, the welfare gain decreases, eventually becomes zero, and then the welfare loss converges to its stationary value. Second, we analyze the effect of the shock on the welfare of different generations. In the multiplicative model, only individuals born in the very first generations are made worse off in the external-habits economy than the corresponding ones in the internal-habits economy. Latter generations may obtain a relatively important welfare gain. Again, the qualitative behavior of generational welfare is extremely dependent on the elasticity of substitution between consumption and habits. Changing this parameter, all generations in the external-habits economy may be made worse off than the corresponding ones in the internal-habits economy, and the latter the generation the larger the welfare loss.

The rest of the paper is organized as follows. Section 2 presents the model. Section 3 analyzes the competitive equilibrium of the market economy, and Section 4, the optimal growth path of the centrally planned economy. Section 5 computes the welfare cost of external and mixed habits, and performs an extensive sensitivity analysis. Section 6 presents some concluding remarks.

\section{THE ModeL}

We study a closed economy populated by $N$ identical infinitely-lived representative agents that grows at the exogenous rate $\dot{N} / N=n$.

\subsection{Preferences}

The instantaneous utility derived by the agent depends both on current consumption, $C$, and a reference consumption level or habits stock, $H$. The intertemporal utility derived by the agent is represented by

$$
U(C)=\int_{0}^{\infty} u(C(t), H(t)) \mathrm{e}^{-\beta t} d t \quad \beta>0
$$


where $\beta$ is the rate of time preference. We consider a general specification of the instantaneous utility function,

$$
u(C, H)=\frac{1}{1-\varepsilon}\left(\frac{C^{\varphi}-\gamma H^{\varphi}}{1-\gamma}\right)^{(1-\varepsilon) / \varphi} \quad \varepsilon>1, \quad 0<\gamma<1, \quad \varphi \geq 0 .
$$

The parameter $\gamma$ reflects the strength of habits, $\varepsilon$ is the coefficient of relative risk aversion when $\gamma=0$, and $\varphi$ determines the elasticity of (intratemporal) substitution between consumption and habits, $1 /(1-\varphi) .^{3}$

If $\varphi=1$, the utility function (2) yields the subtractive specification

$$
u(C, H)=\frac{1}{1-\varepsilon}\left(\frac{C-\gamma H}{1-\gamma}\right)^{1-\varepsilon}=\frac{1}{1-\varepsilon}\left[\frac{(1-\gamma) C+\gamma(C-H)}{1-\gamma}\right]^{1-\varepsilon},
$$

in which individuals derive utility from a weighted arithmetic mean of current consumption and the difference between current consumption and the habits stock. As $\varphi$ goes to zero, the utility function (2) converges to the multiplicative specification

$$
u(C, H)=\frac{1}{1-\varepsilon}\left(C H^{-\gamma}\right)^{(1-\varepsilon) /(1-\gamma)}=\frac{1}{1-\varepsilon}\left[C^{1-\gamma}(C / H)^{\gamma}\right]^{(1-\varepsilon) /(1-\gamma)},
$$

in which individuals derive utility from a weighted geometric mean of current consumption and the ratio between current consumption and the habits stock. Substituting $\varepsilon=\gamma+(1-\gamma) \sigma$, (4) may be rewritten as

$$
u(C, H)=\frac{1}{(1-\gamma)(1-\sigma)}\left(C H^{-\gamma}\right)^{1-\sigma} .
$$

The habits stock is formed as an exponentially declining average of past consumption,

$$
H(t)=\rho \int_{-\infty}^{t} \mathrm{e}^{\rho(s-t)} C(s)^{\phi} \bar{C}(s)^{1-\phi} d s \quad \rho>0, \quad 0 \leq \phi \leq 1,
$$

3 A similar CES utility function has been employed by Dupor and Liu (2003), with $H$ representing externalities associated to current consumption. They assume that $-\infty<\varphi \leq 1$. However, this assumption may lead to the lack of concavity of the instantaneous utility function (2) with respect to consumption $C$, which requires that $\varepsilon C^{\varphi}-\gamma(1-\varphi) H^{\varphi} \geq 0$ for all feasible $(C, H)$; i.e., such that $C^{\varphi}-\gamma H^{\varphi}>0$. Given that $\varepsilon>1$, the assumption $\varphi \geq 0$ ensures strict concavity of $u$ with respect to $C$. Furthermore, $u$ is concave in $(C, H)$ if and only if $\varphi \geq 1$. 
where $\bar{C}$ denotes the economy-wide average consumption. Differentiating (6) with respect to time, the rate of adjustment of the habits stock is

$$
\dot{H}=\rho\left(C^{\phi} \bar{C}^{1-\phi}-H\right) \text {. }
$$

The parameter $\rho>0$, which governs the speed with which the habits stock adjusts to current consumption, determines the relative weight of consumption at different dates: the larger is $\rho$, the more important is consumption in the recent past. As $\rho \rightarrow \propto$ then $H \rightarrow C^{\phi} \bar{C}^{1-\phi}$ so that agent's utility depends only on current consumption. The parameter $\phi$ reflects the weight of own past consumption in habits. Setting $\phi=0$ corresponds to the EH model, in which habits are formed from the economy-wide average past consumption. Setting $\phi=1$ corresponds to the externality-free IH model, in which habits arise from own past consumption.

\subsection{Production}

Each individual inelastically supplies one unit of labor in each period. Individual's gross output, $Y$, is determined by the $\mathrm{AK}$ technology

$$
Y=B K, \quad B>0,
$$

where $K$ is the individual's capital stock.

\subsection{The agent's problem}

The single good of the economy can be either consumed or invested. The agent's budget constraint is, then,

$$
\dot{K}=B K-C-(n+\delta) K=A K-C,
$$

where $\delta$ is the rate of depreciation of capital, and we define $A=B-n-\delta$.

The agent chooses $C, K$ and $H$ to maximize the lifetime utility (1) subject to her budget constraint (9) and the constraint on the habits stock accumulation (7), taking as given the path of average consumption, $\bar{C}$, and the initial conditions on capital, $K(0)>0$, and habits stock, $H(0)>0$.

\section{The Market Economy}

A competitive equilibrium is as a set of paths $\{C(t), K(t), H(t)\}_{t=0}^{\infty}$ that solves the agent's utility maximization problem, and $\bar{C}(t)=C(t)$ at any time. A balanced growth path (BGP) or steady-state equilibrium is a competitive equilibrium along which $C, K$ and $H$ grow at constant rates.

Let $J$ be the current value Hamiltonian of the agent's maximization problem: 


$$
J=u(C, H)+\lambda(A K-C)+\mu \rho\left(C^{\phi} \bar{C}^{1-\phi}-H\right),
$$

where $\lambda$ and $\mu$ are the shadow values of capital and habits stock, respectively. Appendix shows that the dynamic behavior of the economy along an interior solution can be described by the following third-order dynamical system in the variables $c \equiv C / H, h \equiv H / K$ and $q \equiv \mu / \lambda$ :

$$
\begin{gathered}
\dot{c}=\frac{u_{C}(c, 1)}{u_{C C}(c, 1)}\left[\beta-A+\frac{\rho \phi \dot{q}}{1+\rho \phi q}+\varepsilon \rho(c-1)\right], \\
\dot{h}=h[\rho(c-1)-A+c h] \\
\dot{q}=(A+\rho) q+(1+\rho \phi q) \frac{u_{H}(c, 1)}{u_{C}(c, 1)},
\end{gathered}
$$

where $u_{C}(c, 1) / u_{C C}(c, 1)=-c\left(c^{\varphi}-\gamma\right) /\left[\varepsilon c^{\varphi}-\gamma(1-\varphi)\right]$, and $u_{H}(c, 1) / u_{C}(c, 1)=-\gamma c^{1-\varphi}$.

Now, we focus on the BGP at which consumption, capital and habits stock all grow at the same rate. A hat ' $\wedge$ ' over a variable will denote its stationary value. We can state the following proposition.

Proposition 1. The decentralized economy has a unique steady-state equilibrium with positive long-run growth,

$$
\begin{gathered}
\hat{c}=1+\frac{A-\beta}{\varepsilon \rho}=\frac{\rho+\hat{g}}{\rho}, \\
\hat{h}=\frac{A-\rho(\hat{c}-1)}{\hat{c}}=\frac{A-\hat{g}}{\hat{c}}, \\
\hat{q}=-\frac{u_{H}(\hat{c}, 1)}{(A+\rho) u_{C}(\hat{c}, 1)+\rho \phi u_{H}(\hat{c}, 1)}=\frac{\gamma(\hat{g}+\rho)}{(A+\rho) \rho \hat{c}^{\varphi}-(\hat{g}+\rho) \rho \gamma \phi},
\end{gathered}
$$

where the long-run growth rate of consumption, capital and output per capita is

$$
\hat{g}=\frac{A-\beta}{\varepsilon},
$$

if and only if

$$
A>\beta \text {. }
$$


Proof. Eqs. (13), (14) and (15) are obtained from equating (10), (11) and (12) to zero and solving the resulting system. Eq. (16) is obtained from $\hat{g}=\rho(\hat{c}-1)$. Eq. (16) shows that $\hat{g}>0$ if and only if $A>B$, which yields $\hat{c}>1$. Furthermore, $\hat{h}>0$ if and only if $A>\hat{g}$, which is satisfied because it is equivalent to $\beta>(1-\varepsilon) A$. The transversality conditions (A.4) and (A.5) are also satisfied because they can be equivalently expressed as $-\beta+\dot{\hat{\lambda}} / \hat{\lambda}+\dot{\hat{K}} / \hat{K}=-\beta+\dot{\hat{\mu}} / \hat{\mu}+\dot{\hat{H}} / \hat{H}=-A+\hat{g}<0$.

Proposition 1 proves that the steady state is unique and, therefore, the possibility of multiple steady states is ruled out. This result is standard in the AK model with habit formation (e.g., Carroll et al., 1997, 2000, Alonso-Carrera et al., 2005, 2006, Gómez, 2008), and also in the neoclassical growth model with habits (e.g., Alonso-Carrera et al., 2005, Álvarez-Cuadrado et al., 2004, and Gómez, 2007) when labor supply is inelastic. ${ }^{4}$ In contrast, multiple steady states may emerge in the presence of external habits when labor supply is elastic (see, e.g., Chen et al., 2009).

The system (10)-(12) is accessible to phase-diagram analysis. Note first that $u$ is well-defined for all $(C, H)$ such that $C^{\varphi}>\gamma H^{\varphi} ;$ i.e., for all $c$ such that $c>\bar{c}=\gamma^{1 / \varphi}$.

If $\phi=0$ the $\dot{c}=0$-locus is vertical at $c=\hat{c}$ and stable. If $0<\phi \leq 1$, the $\dot{c}=0$ -locus is

$$
q=l_{c}(c)=\frac{1}{\rho \phi}\left\{\frac{A-\beta-\varepsilon \rho(c-1)+\rho \gamma \phi c^{1-\varphi}}{\beta+\rho+\varepsilon \rho(c-1)-\rho \gamma \phi c^{1-\varphi}}\right\}
$$

Since the denominator is strictly increasing for all $c>\gamma^{1 / \varphi}$, the $\dot{c}=0$-locus has at most one vertical asymptote in $c=\bar{c}_{L} \in\left(\gamma^{1 / \varphi}, \infty\right)$. Furthermore, $\bar{c}_{L}<\hat{c}$ because the denominator is positive for all $c \geq \hat{c}$. The $\dot{c}=0$-locus is strictly decreasing since $l_{c}^{\prime}(c)<0$, and stable because $d \dot{c} / d q<0$. Thus, in $(c, q)$-space, the arrows point west (east) above (below) the $\dot{c}=0$-locus. Furthermore, $\lim _{c \rightarrow \infty} l_{c}(c)=-1 /(\rho \phi)=\bar{q}$.

From (12), the $\dot{q}=0$-locus is

$$
q=l_{q}(c)=\frac{\gamma}{(A+\rho) c^{\varphi-1}-\rho \gamma \phi},
$$

and its slope is given by

$4 \quad$ Although Chen (2007) seems to show that multiple steady states may arise in an AK model with habit persistence, Toche (2009) shows that really Chen's model features a unique steady state. 


$$
\frac{d l_{q}}{d c}(c)=\frac{\gamma(A+\rho)(1-\varphi) c^{\varphi-2}}{\left[(A+\rho) c^{\varphi-1}-\rho \gamma \phi\right]^{2}} .
$$

Furthermore, we have that

$$
d \dot{q} / d q=A+\rho-\rho \gamma \phi c^{1-\varphi} .
$$

If $\varphi=1$, the $\dot{q}=0$-locus is constant at $q=\hat{q}$ and unstable. If $\varphi>1$, the $\dot{q}=0$-locus is strictly decreasing in $\left(\gamma^{1 / \varphi}, \infty\right)$, and unstable because $d \dot{q} / d q>A+\rho(1-\phi) \gamma>0$. It has an asymptote at $c=\bar{c}_{M}=[\rho \gamma \phi /(A+\rho)]^{1 /(\varphi-1)}<\gamma^{1 / \varphi}$, because the denominator of (19) is strictly increasing and $(A+\rho) c^{\varphi-1}-\rho \gamma \phi>[A+\rho(1-\phi)] \gamma>0$ for all $c>\gamma^{1 / \varphi}$, with $\lim _{c \rightarrow \infty} l_{q}(c)=0$. If $\varphi<1$, the $\dot{q}=0$-locus is strictly increasing and if $\phi \neq 0$ it has an asymptote at $c=\bar{c}_{M}=[\rho \gamma \phi /(A+\rho)]^{1 /(\varphi-1)}>\hat{c}$, because the denominator of (19) is strictly decreasing and tends to $-\rho \gamma \phi<0$ as $c$ goes to infinity. The $\dot{q}=0$-locus is positive and unstable if $c<\bar{c}_{M}$, and negative and stable if $c>\bar{c}_{M}$, with $\lim _{c \rightarrow \infty} l_{q}(c)=-1 /(\rho \phi)$.

If $0<\phi \leq 1$, it can be easily obtained that

$$
\operatorname{sgn}\left[l_{c}(c)-l_{q}(c)\right]=\operatorname{sgn}\left\{\frac{A-\beta-\varepsilon \rho(c-1)}{\left[(A+\rho) c^{\varphi-1}-\rho \gamma \phi\right]\left[\beta+\rho+\varepsilon \rho(c-1)-\rho \gamma \phi c^{1-\varphi}\right]}\right\},
$$

which entails that the unique intersection between both loci occurs at $c=\hat{c}$.

The top left, top right and bottom left panels of Figure 1 depict phase diagrams in $(c, q)$-space if $\varphi>1, \varphi<1$ and $\varphi=1$, respectively. ${ }^{5}$ Given the configuration of the two loci, the steady state $(\hat{c}, \hat{q})$ is saddle-path stable. The bottom right panel of Figure 1 is a phase diagram in $(c, h)$-space. Given that the economy is on its saddle path in $(c, q)$-space, $c$ converges monotonically, and so, the $\dot{c}=0$ -locus is vertical and stable in $(c, h)$-space. The $\dot{h}=0$-locus is

$$
l_{h}(c)=\frac{A+\rho}{c}-\rho
$$

which is decreasing, convex and unstable, with $\lim _{c \rightarrow 0} l_{h}(c)=\infty>\hat{c}>\lim _{c \rightarrow \infty} l_{h}(c)=-\rho$. Given the configuration of the two loci, the (unique) steady state $(\hat{c}, \hat{h})$ is saddlepath stable. Thus we can state the following proposition.

\footnotetext{
5 To depict Figure 1, we have considered that $0<\phi \leq 1$. If $\phi=0$, the phase diagrams are similar, but now the $\dot{c}=0-$ locus is vertical.
} 


\section{FIGURE 1}

PHASE DIAGRAM

Convergence in $(c, q)$-space
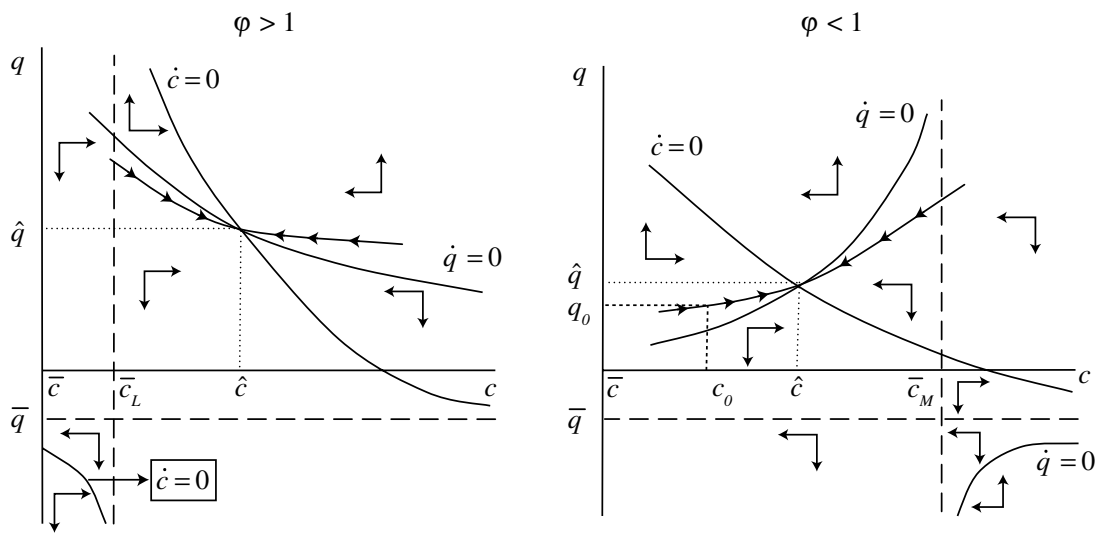

$\varphi=1$

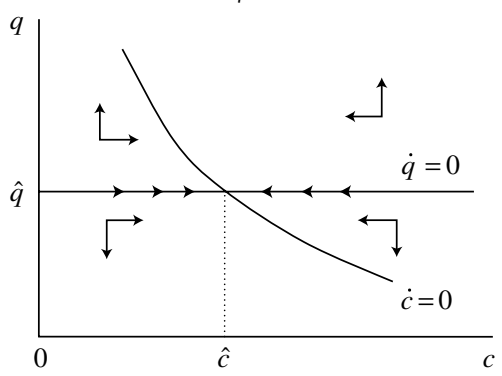

Convergence in $(c, h)$-space

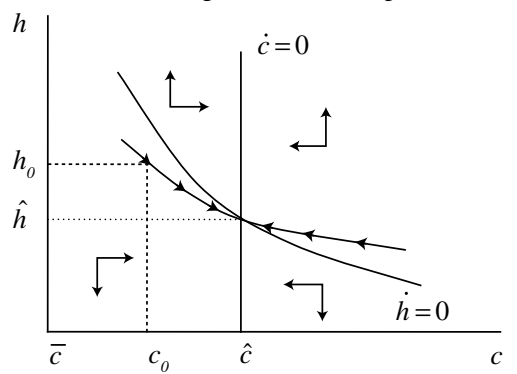

Proposition 2. Let $A>\beta$. The steady state of the decentralized economy described by (13), (14) and (15) is a saddle-point.

The local stability analysis confirms the former result. Linearizing the system (10)-(12) around the steady state (13)-(15), we get

$$
\left(\begin{array}{c}
\dot{c} \\
\dot{h} \\
\dot{q}
\end{array}\right)=\left(\begin{array}{ccc}
d_{11} & 0 & d_{13} \\
\hat{h}(\hat{h}+\rho) & \hat{c} \hat{h} & 0 \\
d_{31} & 0 & d_{33}
\end{array}\right)\left(\begin{array}{c}
c-\hat{c} \\
h-\hat{h} \\
q-\hat{q}
\end{array}\right)=D \cdot\left(\begin{array}{c}
c-\hat{c} \\
h-\hat{h} \\
q-\hat{q}
\end{array}\right),
$$

where

$$
d_{11}=\frac{u_{C}(\hat{c}, 1)}{u_{C C}(\hat{c}, 1)}\left[\varepsilon \rho+\left(\frac{\rho \phi}{1+\rho \phi \hat{q}}\right) d_{31}\right] \text {, }
$$




$$
\begin{gathered}
d_{13}=\frac{u_{C}(\hat{c}, 1)}{u_{C C}(\hat{c}, 1)}\left(\frac{\rho \phi}{1+\rho \phi \hat{q}}\right) d_{33}, \\
d_{31}=(1+\rho \phi \hat{q})\left\{\frac{u_{C H}(\hat{c}, 1) u_{C}(\hat{c}, 1)-u_{C C}(\hat{c}, 1) u_{H}(\hat{c}, 1)}{\left[u_{C}(\hat{c}, 1)\right]^{2}}\right\}= \\
=-(1+\rho \phi \hat{q}) \frac{\gamma(\varepsilon-1)(\varphi-1)}{2 \hat{c}\left(\hat{c}^{\varphi}-\gamma\right)} \\
d_{33}=-\frac{u_{H}(\hat{c}, 1)}{\hat{q} u_{C}(\hat{c}, 1)}=\frac{\gamma \hat{c}^{1-\varphi}}{\hat{q}}>0,
\end{gathered}
$$

The last inequality follows from $\hat{q}>0$ because, using $A>\hat{g}$ and $\hat{c}>1$, we have that

$$
(A+\rho) \rho \hat{c}^{\varphi}-(\hat{g}+\rho) \rho \gamma \phi>(\hat{g}+\rho) \rho\left(\hat{c}^{\varphi}-\gamma \phi\right)>(\hat{g}+\rho) \rho(1-\gamma \phi)>0 .
$$

Given the structure of the matrix $D$, the second diagonal element, $\hat{c} \hat{h}$, is an unstable root. The other two roots are those of the submatrix

$$
D_{13}=\left(\begin{array}{ll}
d_{11} & d_{13} \\
d_{31} & d_{33}
\end{array}\right) \text {. }
$$

The determinant of $D_{13}$ is $\operatorname{det}=\varepsilon \rho d_{33} u_{C}(\hat{c}, 1) / u_{C C}(\hat{c}, 1)<0$. Hence, $D$ has one stable (real) root and two instable (real) roots, which proves that the steady state is locally saddle-point stable.

\section{The Centrally Planned Economy}

The central planner possesses complete information and chooses all quantities directly, taking all the relevant information into account. The agent chooses $C, K$ and $H$ to maximize the agent's lifetime utility (1) subject to the resources' constraint (9) and the constraint on the habits stock accumulation

$$
\dot{H}=\rho(C-H),
$$

taking as given $K(0)>0$ and $H(0)>0$. An optimal growth path is as a set of paths $\{C(t), K(t), H(t)\}_{t=0}^{\infty}$ that solves the planner's utility maximization problem.

It can be readily observed that the planner's problem in the centrally planned economy coincides with the agent's problem in the market economy when $\phi=1$. Hence, the optimal growth path of the centralized economy coincides with the competitive equilibrium of the (efficient) externality-free IH economy, and the system that drives the dynamics of the centrally planned economy in terms of the variables $c, h$ and $q$ is given by (10), (11) and (12) with $\phi=1$. Propositions 1 and 2 can be readily specialized to the case of the 
centrally planned economy. A bar over a variable will denote its steady state in the centralized economy.

Proposition 3. The centrally planned economy has a unique and locally saddlepath stable steady-state equilibrium with positive long-run growth,

$$
\begin{gathered}
\bar{c}=1+\frac{A-\beta}{\varepsilon \rho}=\frac{\rho+\bar{g}}{\rho}, \\
\bar{h}=\frac{A-\rho(\bar{c}-1)}{\bar{c}}=\frac{A-\bar{g}}{\bar{c}}, \\
\bar{q}=-\frac{u_{H}(\bar{c}, 1)}{(A+\rho) u_{C}(\bar{c}, 1)+\rho u_{H}(\bar{c}, 1)}=\frac{\gamma(\bar{g}+\rho)}{(A+\rho) \rho \bar{c} \varphi-(\bar{g}+\rho) \rho \gamma},
\end{gathered}
$$

where the long-run growth rate of consumption, capital and output per capita is

$$
\bar{g}=\frac{A-\beta}{\varepsilon},
$$

if and only if $A>\beta$.

\section{Welfare Analysis}

This section provides a quantitative assessment of the welfare cost of external (or mixed) habits. To this end, we perform an exercise similar to that in Carroll et al. (1997), and consider the effect of a 10 percent unanticipated reduction in the capital stock of an economy that was initially on its balanced growth path. For comparative purposes, we also study the effect of a larger reduction of 25 percent in the capital stock. We compute the welfare loss in the EH/MH market economy relative to the centrally planned economy -i.e., the efficient externalityfree IH market economy- after the shock. The welfare loss is measured as the percentage reduction in the flow of consumption in the IH economy required to equate the level of welfare to that in the EH/MH economy. Let $C_{E}(t)$ and $H_{E}(t)$ denote the time paths of consumption and habits in the $\mathrm{EH} / \mathrm{MH}$ economy after the shock, and let $C_{I}(t)$ and $H_{I}(t)$ denote the corresponding ones in the IH economy. If the shock that reduces the capital stock occurs at time $t=0$, the welfare cost of external habits is the value $\kappa$ such that

$$
\int_{0}^{\infty} u\left((1-\kappa) C_{I}(t), H_{I}(t)\right) \mathrm{e}^{-\beta t} d t=\int_{0}^{\infty} u\left(C_{E}(t), H_{E}(t)\right) \mathrm{e}^{-\beta t} d t
$$

It should be noted that after the shock, both the market and the centrally planned economies converge to their common pre-shock steady state. Rather than relying on linear approximations, we explicitly solve for the non-linear 
transitional dynamics by using the backward integration method (Brunner and Strulik, 2002, Atolia and Buffie, 2009).

The baseline parameter values displayed in Table 1 are those employed by Carroll et al. (1997). ${ }^{6}$ They consider the utility function (5) with $\sigma=2$ and, therefore, the corresponding value of $\varepsilon$ in Table 1 for the equivalent specification (4) is $\varepsilon=\gamma+(1-\gamma) \sigma=1.5$. The baseline parameterization entails that habits are purely external. The implied long-run growth rate is $\hat{g}=\bar{g}=0.02$. In the following Figures, the solid (dotted) line corresponds to the case of a $10 \%$ $(25 \%)$ drop in the capital stock.

TABLE 1

BENCHMARK CALIBRATION

\begin{tabular}{|cll|}
\hline Parameter & Value & \multicolumn{1}{c|}{ Interpretation } \\
\hline$A$ & 0.08 & Net scale parameter in the goods sector \\
$\beta$ & 0.05 & Rate of time preference \\
$\varepsilon$ & 1.5 & Relative risk aversion \\
$\gamma$ & 0.5 & Strength of habits in utility \\
$\rho$ & 0.2 & Speed of adjustment of habits \\
$\phi$ & 0 & Weight of own past consumption in habits \\
$\varphi$ & 0 & Elasticity of intratemporal substitution parameter \\
\hline
\end{tabular}

The top panels of Figure 2 display the welfare cost of external habits as the speed of adjustment $\rho$ varies from 0 to 4 , while the remaining parameter values are maintained at their baseline values reported in Table 1. We display the results for the multiplicative case, $\varphi=0$, and the case that $\varphi=2 .{ }^{7}$ As $\rho$ increases, the welfare loss first increases from zero to its maximum value, and then decreases steadily toward zero as $\rho$ goes to infinity. If $\rho=0$, the habit stock is constant and, therefore, both the $\mathrm{EH}$ and $\mathrm{IH}$ models become equivalent to the conventional AK model. Hence, consumption externalities do not provoke inefficiency and the welfare loss is zero. As $\rho$ tends to infinity, Carroll et al. (1997) show that the habits stock tends to a weighted geometric average of own and economy-wide average current consumption, $H=C^{\phi} \bar{C}^{1-\phi}$, so that the model collapses to a model with contemporaneous consumption externalities. This kind of externalities does not provoke inefficiency (e.g., Liu and Turnovsky, 2005), and so the welfare loss tends to zero as $\rho$ goes to infinity (not displayed in the Figure).

$6 \quad$ Eqs. (10)-(12) and (13)-(15) show that the parameters $B, n$ and $\delta$ affect the dynamics and the steady state of the economy only through the value of $A=B-n-\delta$ which, therefore, is the relevant parameter. Different combinations of $B, n$ and $\delta$ can lead to the value of $A=0.08$ shown in Table 1. For example, Carroll et al. (1997) consider $B=0.13, n=0$ and $\delta=0.05$.

7 In a similar discrete-time multiplicative model, $\varphi=0$, Alonso-Carrera et al. (2005) show that the interior solution characterized by the first-order conditions will indeed be a maximum if $\varepsilon>1$. If $\varphi=2$, the Hamiltonian is concave in $(C, H)$ and, therefore, the necessary conditions are also sufficient. 
FIGURE 2

WELFARE LOSS IN THE EH ECONOMY RELATIVE TO THE IH ECONOMY

(In percent)
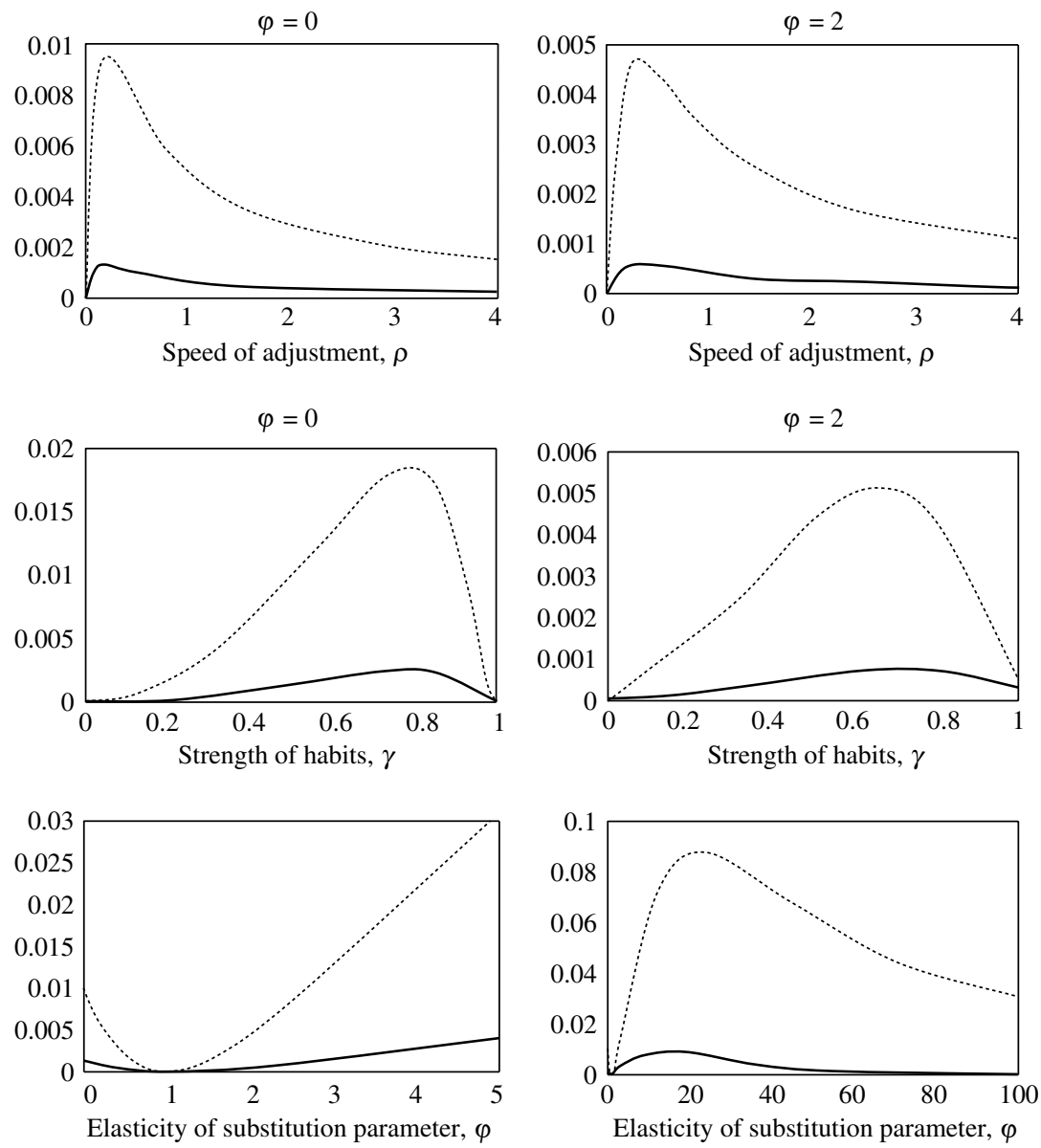

$10 \%$ reduction in capital stock

$25 \%$ reduction in capital stock

The medium panels of Figure 2 display the welfare loss after the capital shock as the parameter of strength of habits in utility $\gamma$ varies from 0 to 1 , while the remaining parameters are maintained at their baseline values displayed in Table $1 .{ }^{8}$ If $\gamma=0$, habits do not enter utility. Hence, the equilibrium dynamics

8 Carroll et al. (2000) analyze the dynamics of the IH economy for different values of $\gamma$, where utility is specified as (5). In their simulations, for each value of $\gamma$, the value of $\sigma$ is chosen to keep the steady state which the economy converges to unchanged; i.e., such that $\varepsilon=\gamma+(1-\gamma) \sigma$ is constant. This is equivalent to use the multiplicative specification (4). 
of the IH and $\mathrm{EH}$ economies coincide and, therefore, the welfare cost is zero. As $\gamma$ increases, the welfare loss first increases from zero to its maximum value, and then decreases steadily as $\gamma$ goes to 1 . The bottom panels of Figure 2 display the welfare cost of external habits as the elasticity of substitution parameter $\varphi$ increases, keeping constant the remaining parameters at their baseline values shown in Table 1 . As $\varphi$ increases from 0 to 1 , the welfare loss decreases and it even becomes zero in the subtractive model, $\varphi=1$. This entails that in the subtractive economy, the competitive equilibrium is efficient. ${ }^{9}$ As $\varphi$ increases from 1 the welfare loss increases until it reaches its maximum level at around $\varphi=15$ (resp., $\varphi=23$ ) and then decreases steadily toward 0 as $\varphi$ goes to infinity. The reason is that as $\varphi$ goes to infinity, the utility function (2) tends to $u(C, H)=C^{1-\varepsilon} /(1-\varepsilon)$. Hence, utility does not depend on the habits stock and, therefore, the welfare loss is zero.

Although the overall effect on welfare of the capital shock is quite similar in the $\mathrm{EH}$ and $\mathrm{IH}$ economies, there could be significant differences in its timing. Let $V(T, \varphi)$ denote the utility attained at time $T$ following a capital shock at time $t=0$, for a given value of the parameter $\varphi$,

$$
V(T, \varphi)=\int_{0}^{T} u(C(t), H(t)) \mathrm{e}^{-\beta t} d t
$$

Now, we shall focus on the two extreme cases of internal and external habits. Figure 3 illustrates the time path of the welfare loss in the EH economy relative to the IH economy when $\varphi=0$ and $\varphi=2$, while the remaining parameter values are maintained at their baseline values shown in Table 1 . When $\varphi=0$, after a $10 \%$ (resp., 25\%) destruction of the stock of capital, welfare in the EH economy is always lower than that in the IH economy. The highest welfare loss of $0.91 \%$ (resp., $2.38 \%$ ) is generated on impact. Thereafter, it decreases steadily toward its stationary value of $0.001 \%$ (resp., $0.01 \%$ ) as time goes to infinity. In contrast, when $\varphi=2$, after a $10 \%$ (resp., $25 \%$ ) destruction of the stock of capital, the EH economy has a welfare gain relative to the IH economy of $0.35 \%$ (resp., $0.76 \%$ ) on impact. Thereafter, the welfare gain decreases steadily, becomes negative (i.e., a loss) and then the welfare loss converges toward its stationary value of $0.0006 \%$ (resp., $0.004 \%$ ) as time goes to infinity.

Another interesting question is whether generational welfare is affected by the specification of habits. Following Grüner and Heer (2000), the integral

$$
W(T, \varphi)=\int_{T}^{\infty} u(C(t), H(t)) \mathrm{e}^{-\beta t} d t
$$

can be interpreted as the utility of an individual born at time $T$ for a given value of $\varphi$.

9 In the subtractive model, $\varphi=1$, the welfare loss is found to be zero for every parameter configuration. The competitive equilibrium of the EH/MH economy coincides with the optimal growth path of the centrally planned economy, and so, it is efficient. This is the reason why the subtractive case is not depicted in the Figures. 


\section{FIGURE 3}

TIME PATH OF WELFARE LOSS IN THE EH ECONOMY RELATIVE TO THE IH ECONOMY

(In percent)

$\varphi=0$

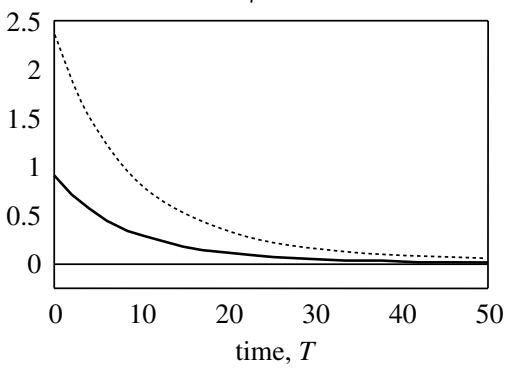

$10 \%$ reduction in capital stock $\varphi=2$

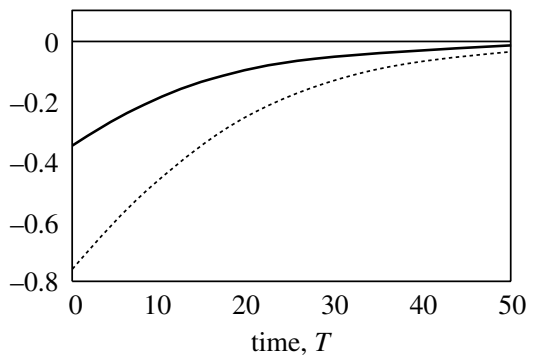

$25 \%$ reduction in capital stock

FIGURE 4

GENERATIONAL WELFARE LOSS IN THE EH ECONOMY RELATIVE TO THE IH ECONOMY

(In percent)

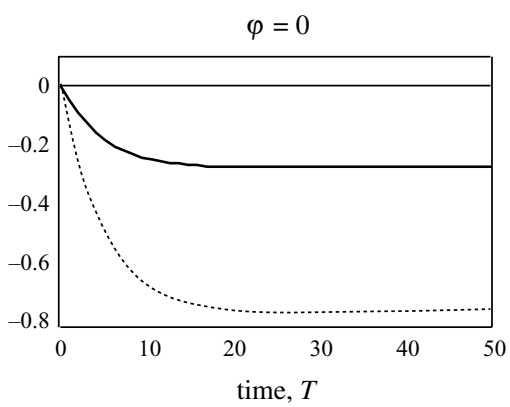

$-10 \%$ reduction in capital stock

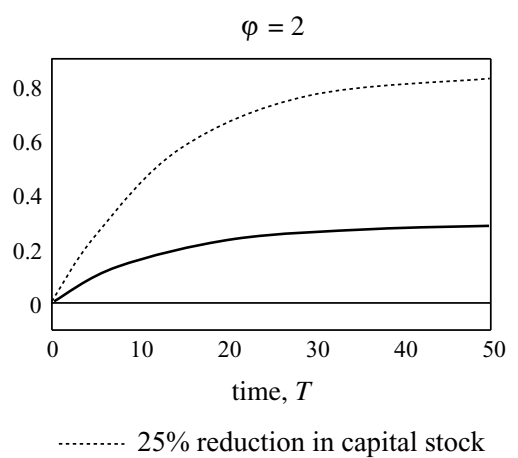

Figure 4 depicts the generational welfare loss (or gain) in the EH economy relative to the IH economy when $\varphi=0$ and $\varphi=2$, while the remaining parameter values are maintained at their baseline values shown in Table 1 . When $\varphi=0$, after a $10 \%$ (resp., 25\%) reduction in the capital stock, only individuals born in the initial 0.024 (resp., 0.067) periods in the IH economy are made better off than the corresponding ones in the EH economy. From then on, generational welfare is higher in the EH economy than that in the IH economy, and the welfare gain is relatively important. For example, for individuals born in period $T=25$, the welfare gain in the EH economy relative to the IH economy amounts to $0.27 \%$ (resp., $0.76 \%$ ). This results contrast markedly with those obtained when $\varphi=2$. In this case, after a 10\% (resp., 25\%) reduction in the capital stock, generational welfare in the EH economy is lower than that in the IH economy whatever the 
FIGURE 5

CONSUMPTION IN THE EH ECONOMY RELATIVE TO THE IH ECONOMY

(Ratio)

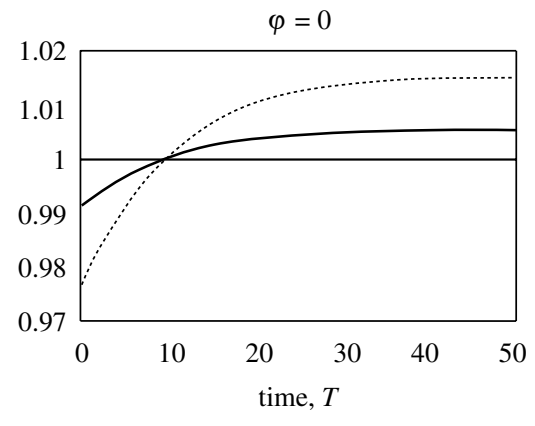

$10 \%$ reduction in capital stock

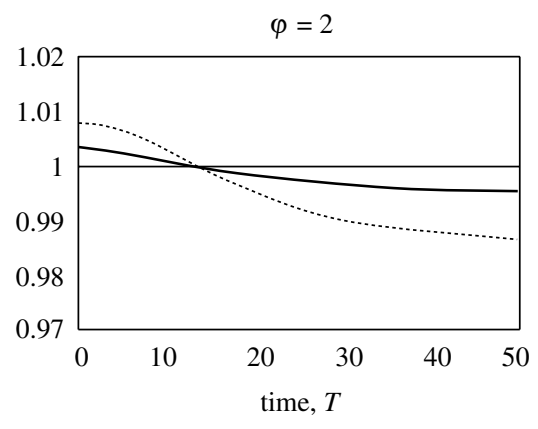

$25 \%$ reduction in capital stock

generation considered. Furthermore, the generational welfare loss increases steadily as the time $T$ increases, and it could be relatively important. For example, for individuals born in period $T=25$, the welfare loss in the EH economy relative to the IH economy amounts to $0.25 \%$ (resp., $0.73 \%$ ).

The former results reveal that, although the overall welfare cost of external habits is quantitatively unimportant, there are differences in welfare timing and generational welfare that can be rather significant from a quantitative viewpoint. This qualifies somewhat the conclusion that consumption externalities in habit formation models are irrelevant for welfare. Furthermore, the elasticity of substitution between consumption and habits plays an important role in the qualitative behavior of welfare timing and generational welfare.

The dynamic path of welfare and the behavior of generational welfare can be more easily understood by looking at Figure 5, which depicts the ratio of consumption in the EH economy relative to that in the IH economy. The time path of consumption is similar in both economies. In the multiplicative model, $\varphi=0$, after a 10 percent (resp., 25 percent) reduction in the capital stock, consumption in the EH economy is lower than that in the IH economy during the first 9.7 periods (resp., 9.8 periods) and, from that time on, is higher than that. Since the greatest difference in consumption levels happens at the initial time, the highest welfare loss in the EH economy relative to the IH economy is generated on impact. As the economy evolves, consumption in the EH economy catches up and, eventually, exceeds consumption in the IH economy. As a consequence, the welfare loss in the EH economy relative to the IH economy decreases steadily toward its stationary value. This also explains that generational welfare in the EH economy is higher than that in the IH economy for nearly all generations, except for the very first ones. These results are in sharp contrast with the ones obtained in the case that $\varphi=2$. Now, consumption in the EH economy is higher than that in the IH economy during the first 12.8 periods (resp, 13.4 periods) and, from that time on, is lower than that. Since the greatest difference in consumption levels occurs at the initial time, the highest welfare gain in the EH 
economy relative to the IH economy is generated on impact. As the economy evolves, consumption in the IH economy catches up and, eventually exceeds consumption in the EH economy. As a consequence, the welfare gain in the $\mathrm{EH}$ economy relative to the IH economy decreases steadily and, eventually, becomes a welfare loss that converges toward its stationary value. Furthermore, generational welfare in the $\mathrm{EH}$ economy is lower than that in the $\mathrm{IH}$ economy for all generations. ${ }^{10}$

The different dynamic behavior of consumption in the EH economy relative to the IH economy between the cases $\varphi=2$ and $\varphi=0$ shown in Figure 5 can be explained by the relationship between the intertemporal marginal rates of substitution (MRS) of consumption in the IH and EH economies. The MRS between consumption at times $t_{1}$ and $t_{2}$, with $t_{2}>t_{1}$, is

$$
\begin{aligned}
\operatorname{MRS}_{t_{1}, t_{2}}= & \frac{\partial U(C) / \partial C\left(t_{2}\right)}{\partial U(C) / \partial C\left(t_{1}\right)}= \\
= & \frac{u_{C}\left(C\left(t_{2}\right), H\left(t_{2}\right)\right) e^{-\beta t_{2}}+\phi \rho e^{\rho t_{2}} \int_{t_{2}}^{\infty} e^{-(\beta+\rho) t} u_{H}(C(t), H(t)) d t}{u_{C}\left(C\left(t_{1}\right), H\left(t_{1}\right)\right) e^{-\beta t_{1}}+\phi \rho e^{\rho t_{1}} \int_{t_{1}}^{\infty} e^{-(\beta+\rho) t} u_{H}(C(t), H(t)) d t}
\end{aligned}
$$

where $\partial U(C) / \partial C(t)$ denotes the Volterra derivative of $U(C)$-defined in (1)with respect to consumption at time $t$. Using (A.6) and (A.7) we get

$$
\operatorname{MRS}_{t_{1}, t_{2}}=\frac{u_{C}\left(C\left(t_{2}\right), H\left(t_{2}\right)\right)}{u_{C}\left(C\left(t_{1}\right), H\left(t_{1}\right)\right)} \frac{\left[1+\rho \phi q\left(t_{1}\right)\right]}{\left[1+\rho \phi q\left(t_{2}\right)\right]} e^{-\beta\left(t_{2}-t_{1}\right)} .
$$

Consider first that $\varphi>1$. After a reduction in capital stock, the economy starts with a level of $h$ above its steady-state value. Figure 1 shows that as the economy evolves $h$ decreases and $c$ increases monotonically toward their respective steady-state values. As Carroll et al. (1997) argue, the agent maintains a low level of $c \equiv C / H$ relative to its steady-state value because this allows decreasing $h \equiv H / K$ by fostering capital accumulation and by slowing the growth of the habits stock. As $h$ approaches its stationary value, consumption needs to be depressed less, so $c$ grows toward its steady state. Figure 1 also shows that the relative cost of habits, $q$, decreases steadily toward its stationary value. Hence, (27) entails that the MRS in the EH economy would be lower than that in the IH economy, $\mathrm{MRS}_{t_{1}, t_{2}}^{\mathrm{EH}}<\mathrm{MRS}_{t_{1}, t_{2}}^{\mathrm{IH}}$, when evaluated along the equilibrium path of

10 Following Carroll et al. (2000), we have also computed the effect of an unanticipated but permanent increase in the productivity parameter $B$ (or, equivalently, in $A$ ) such that the steady-state growth rate of the economy increases from 1 percent to 2 percent. The results obtained are qualitatively similar, but quantitatively even of less magnitude, to those obtained in the present paper for a capital drop. Results are available upon request. 
the IH economy. A lower MRS means that the agent is less willing to substitute present by future consumption. Thus the transition in the EH economy is characterized by initial over-consumption relative to the IH economy, followed by subsequent under-consumption, as shown in Figure 5 when $\varphi=2$. The opposite occurs when $\varphi<1$ (see the case $\varphi=0$ in Figure 5). Now, $q$ is increasing and, therefore, $\mathrm{MRS}_{t_{1}, t_{2}}^{\mathrm{EH}}>\mathrm{MRS}_{t_{1}, t_{2}}^{\mathrm{IH}}$. Hence, the desire to substitute intertemporally in the EH economy would be higher than that in the IH economy.

\section{Concluding Remarks}

This paper quantifies the welfare cost of consumption externalities in an endogenous growth model with habit formation. Although utility is lower in the model with external or mixed habits than in the model with internal habits because of the presence of a negative externality, the welfare loss is insignificant. This result is extremely robust to parameter variations. Hence, the specification of habits as external or internal could seem to be irrelevant from a welfare perspective. However, this conclusion should be somewhat qualified because of the relatively important differences arising in the welfare timing and in generational welfare.

\section{REFERENCES}

Abel, A. (1990). "Asset prices under habit formation and catching up with the Joneses", American Economic Review, Vol. 80; 38-42.

Alonso-Carrera, J.; Caballé, J. and Raurich, X. (2005). "Growth, habit formation, and catching-up with the Joneses", European Economic Review, Vol. 49; 1665-1691.

Alonso-Carrera, J.; Caballé, J. and Raurich, X. (2006). "Welfare implications of the interaction between habits and consumption externalities", International Economic Review, Vol. 47; 557-571.

Álvarez-Cuadrado, F.; Monteiro, G. and Turnovsky, S.J. (2004). "Habit formation, catching-up with the Joneses, and economic growth", Journal of Economic Growth, Vol. 9; 47-80.

Atolia, M. and Buffie, E. (2009). "Reverse shooting made easy: Automating the search for the global nonlinear saddle path", Computational Economics, Vol. 34; 273-308.

Boldrin, M.; Christiano, L.J. and Fisher, J.D.M. (2001). "Habit persistence, asset returns and the business cycle", American Economic Review, Vol. 91; 149-166.

Brunner, M. and Strulik, H. (2002). "Solution of perfect foresight models: a simple method and applications", Journal of Economic Dynamics and Control, Vol. 26; 737-753. 
Buraschi, A. and Jiltsov, A. (2007). "Habit formation and macroeconomic models of the term structure of interest rates", Journal of Finance, Vol. 62; 3009-3063.

Campbell, J. and Cochrane, J. (1999). "By force of habit: A consumption-based explanation of aggregate stock market behaviour", Journal of Political Economy, Vol. 107; 205-251.

Carroll, C.D.; Overland, J. and Weil, D.N. (1997). "Comparison utility in a growth model", Journal of Economic Growth, Vol. 2; 339-367.

Carroll, C.D.; Overland, J. and Weil, D.N. (2000). "Saving, growth and habit formation", American Economic Review, Vol. 90; 341-355.

Chen, B.-L. (2007). "Multiple BGPs in a growth model with habit persistence", Journal of Money, Credit and Banking, Vol. 39; 25-48.

Chen, B.-L.; Hsu, Y.-H. and Mino, K. (2009). "Are spillovers of consumption standards really a source of equilibrium indeterminacy?", Working Paper.

Constantinides, G.M. (1990). "Habit formation: A resolution of the equity premium puzzle", Journal of Political Economy, Vol. 98; 519-543.

Diaz, A.; Pijoan-Mas, J. and Rios-Rull, J.V. (2003). "Precautionary savings and wealth distribution under habit formation preferences", Journal of Monetary Economics, Vol. 50; 1257-1291.

Dupor, B. and Liu, W.-F. (2003). "Jealousy and equilibrium overconsumption", American Economic Review, Vol. 93; 423-428.

Ferraguto, G. and Pagano, P. (2003). "Endogenous growth with intertemporally dependent preferences", Contributions to Macroeconomics, Vol. 3 (1), article 10.

Fuhrer, J.C. (2000). "Habit formation in consumption and its implications for monetary policy models", American Economic Review, Vol. 90; 367-390.

Gómez, M.A. (2006). "Optimal consumption taxation in a model of endogenous growth with external habit formation", Economics Letters, Vol. 93; 427-435.

Gómez, M.A. (2007). "Equilibrium efficiency in the Ramsey model with habit formation", Studies in Nonlinear Dynamics \& Econometrics, Vol. 11 (2), article 2 .

Gómez, M.A. (2008). “Convergence speed in the AK endogenous growth model with habit formation", Economics Letters, Vol. 100; 16-21.

Grüner, H. S. and Heer, B. (2000). "Optimal flat-rate taxes on capital -a reexamination of Lucas' supply side model”, Oxford Economic Papers, Vol. 52; 289-305.

Lettau, M. and Uhlig, H. (2000). "Can habit formation be reconciled with business cycles facts?", Review of Economic Dynamics, Vol. 3; 79-99.

Liu, W.F. and Turnovsky, S.J. (2005). "Consumption externalities, production externalities, and long-run macroeconomic efficiency”, Journal of Public Economics, Vol. 89; 1097-1129.

Mansoorian, A. and Michelis, L. (2005). "Money, habits and growth", Journal of Economic Dynamics and Control, Vol. 29; 1267-1285. 
Rebelo, S. (1991). "Long-run policy and long-run growth", Journal of Political Economy, Vol. 99; 500-521.

Shieh, J.; Lai, C. and Chang, W. (2000). "Addictive behavior and endogenous growth", Journal of Economics, Vol. 72; 263-273.

Toche, P. (2009). "Multiple BGPs in a growth model with habit persistence: A comment", Journal of Money, Credit and Banking, Vol. 41; 189-195.

Tsoukis, C. (2007). "Keeping up with the Joneses, growth, and distribution", Scottish Journal of Political Economy, Vol. 54; 575-600.

Turnovsky, S.J. and Monteiro, G. (2007). "Consumption externalities, production externalities, and efficient capital accumulation under time-dependent preferences", European Economic Review, Vol. 51; 479-504. 


\section{APPENDIX}

\section{DERIVATION OF THE COMPETITIVE EQUILIBRIUM}

Let $J$ be the current value Hamiltonian of the agent's maximization problem:

$$
J=u(C, H)+\lambda(A K-C)+\mu \rho\left(C^{\phi} \bar{C}^{1-\phi}-H\right) .
$$

The first-order conditions for an interior optimum are

$$
\begin{gathered}
u_{C}(C, H)+\rho \mu \phi C^{\phi-1} \bar{C}^{1-\phi}=\lambda, \\
A=\beta-\dot{\lambda} / \lambda, \\
u_{H}(C, H) / \mu-\rho=\beta-\dot{\mu} / \mu,
\end{gathered}
$$

and the transversality conditions

$$
\begin{aligned}
& \lim _{t \rightarrow \infty} e^{-\beta t} \lambda K=0, \\
& \lim _{t \rightarrow \infty} e^{-\beta t} \mu H=0 .
\end{aligned}
$$

Eq. (A.1) equates the marginal utility of consumption, adjusted by its effect on the future habits stock, to the shadow price of capital. Eq. (A.2) equates the rate of return on capital to the rate of return on consumption. From (A.3) and (A.5), we can get

$$
\mu(t)=\int_{t}^{\infty} e^{-(\beta+\rho)(s-t)} u_{H}(C(s), H(s)) d s .
$$

This condition states that the shadow value of the habits stock is determined as the present discounted value of the stream of extra utils that would be gained (or lost) by a marginal unit of habits, which depreciates at the rate $\rho$.

Henceforth, we take into account that $\bar{C}=C$ in a symmetric equilibrium. Eq. (A.1) can be rewritten as

$$
u_{C}(C, H)+\rho \phi \mu=\lambda .
$$

Defining $q \equiv-\mu / \lambda$, using (A.7) we can get

$$
\begin{gathered}
\lambda=u_{C}(C, H) /(1+\rho \phi q), \\
\mu=-q u_{C}(C, H) /(1+\rho \phi q) .
\end{gathered}
$$


Differentiating (A.7) with respect to time, we get

$$
\begin{aligned}
& u_{C C}(C, H) \dot{C}+u_{C H}(C, H) \dot{H}=\dot{\lambda}(1+\rho \phi q)+\lambda \rho \phi \dot{q}= \\
& =\left(\beta-A+\frac{\rho \phi \dot{q}}{1+\rho \phi q}\right) u_{C}(C, H),
\end{aligned}
$$

where the last equality follows from using (A.2) to eliminate $\dot{\lambda}$, and then, substituting $\lambda$ for (A.8). Rearranging terms, Eq. (A.10) can be rewritten as

$$
\dot{C}=\frac{u_{C}(C, H)}{u_{C C}(C, H)}\left(\beta-A+\frac{\rho \phi \dot{q}}{1+\rho \phi q}-\frac{u_{C H}(C, H)}{u_{C}(C, H)} \dot{H}\right) .
$$

The system (10), (11) and (12) that drives the dynamics of the market economy in terms of $c \equiv C / H, h \equiv H / K$ and $q$ can be obtained as follows. Since $\dot{c} / c=\dot{C} / C-\dot{H} / H$, from (A.11) and using the homogeneity of degree $-\varepsilon$ of $u_{C}$, we get

$$
\frac{\dot{c}}{c}=\frac{u_{C}(c, 1)}{c u_{C C}(c, 1)}\left(\beta-A+\frac{\rho \phi \dot{q}}{1+\rho \phi q}-\frac{u_{C H}(c, 1)}{u_{C}(c, 1)} \frac{\dot{H}}{H}\right)-\frac{\dot{H}}{H},
$$

which using that $c u_{C C}(c, 1)+u_{C H}(c, 1)=-\varepsilon u_{C}(c, 1)$, can be rewritten as

$$
\frac{\dot{c}}{c}=\frac{u_{C}(c, 1)}{c u_{C C}(c, 1)}\left(\beta-A+\frac{\rho \phi \dot{q}}{1+\rho \phi q}+\varepsilon \frac{\dot{H}}{H}\right) .
$$

Using (7), we finally get Eq. (10). Since $\dot{h} / h=\dot{H} / H-\dot{K} / K$, Eq. (11) results from (7) and (9). Since $\dot{q} / q=\dot{\mu} / \mu-\dot{\lambda} / \lambda$, Eq. (12) results from (A.3) and (A.2), taking into account (A.8) and (A.9). 